\title{
Anxiety and functional disability in a large sample of children and adolescents with chronic pain
}

\author{
Laura E Simons PhD, Christine B Sieberg PhD, Robyn Lewis Claar PhD
}

\author{
LE Simons, CB Sieberg, RL Claar. Anxiety and functional \\ disability in a large sample of children and adolescents with chronic \\ pain. Pain Res Manage 2012;17(2):93-97.
}

BACKGROUND: Anxiety is the most common psychiatric condition in children and adolescents, and is linked to significant disruptions across domains of function. Due to the avoidant nature of anxiety and painrelated disability, studying anxiety symptoms in children with chronic and recurrent pain conditions is important.

OBJECTIVES: To examine anxiety symptoms in a large cohort of children and adolescents evaluated for complex chronic and recurrent pain conditions.

METHODS: Through retrospective chart review, data on anxiety, pain and functional disability were collected from 655 children evaluated at a multidisciplinary pain clinic over a three-year period.

RESULTS: Approximately $11 \%$ of children and adolescents reported clinically elevated anxiety symptoms, with elevated levels across dimensions of anxiety ranging from $14 \%$ (social anxiety, worry) to $27 \%$ (physiological). In addition, a notable $31 \%$ of the sample potentially minimized their anxiety by responding in a socially desirable manner. Anxiety was linearly associated with greater pain-related functional disability, but was not directly correlated with pain. Moderation analyses revealed that at low levels of worry, higher levels of pain were associated with greater functional disability, whereas at high levels of worry, pain no longer predicted the level of functional disability.

CONCLUSIONS: These findings document the prevalence of anxiety in children and adolescents with chronic pain, and also extend recent studies examining the complex relationships among pain, anxiety and pain-related disability.

Key Words: Adolescents; Anxiety; Chronic pain; Functional disability; Psychosocial functioning

$\mathrm{A}$ nxiety is the most common psychiatric condition in youth. The combined one-year prevalence rate of anxiety disorders among children and adolescents is $13 \%$ (1). Children and adolescents with anxiety often struggle with typical developmental tasks such as socializing with friends, attending school and participating in family activities. They often choose to avoid these tasks, resulting in significant disruptions across social, academic and family domains (2). Pediatric patients with chronic pain often exhibit similar patterns of activity avoidance, and anxiety and pain are highly prevalent comorbid conditions in some patient groups.

Clinically elevated levels of anxiety vary widely across pain conditions, with high rates found among children with noncardiac chest pain $(56 \%$ to $81 \%)(3,4)$, abdominal pain (45\%) (5) and fibromyalgia (58\%) (6), while more moderate to low rates have been found among children with complex regional pain syndrome (20\%) (7), unexplained pain $(18 \%)$ (8) and headache (6\%) (9). Studies examining anxiety symptoms in tertiary care chronic pain clinics that serve a broad range of patients have found that overall these patients report higher levels of anxiety symptoms than nonclinical samples of children, but as a group, these patients do not report levels equivalent to youth with anxiety disorders $(10,11)$. Although anxiety and pain have been identified as comorbidities among subgroups of pediatric pain patients and,

\section{L'anxiété et l'incapacité fonctionnelle dans un vaste échantillon d'enfants et d'adolescents souffrant de douleur chronique}

HISTORIQUE : L'anxiété est le principal problème d'ordre psychiatrique chez les enfants et les adolescents, et il s'associe à des perturbations importantes des domaines de fonction. Puisque l'anxiété et les invalidités liées à la douleur suscitent des comportements d'évitement, il est important d'étudier les symptômes d'anxiété chez les enfants ayant des maladies entraînant des douleurs chroniques et récurrentes.

OBJECTIFS : Examiner les symptômes d'anxiété dans une vaste cohorte d'enfants et d'adolescents évalués en raison de maladies complexes entraînant des douleurs chroniques et récurrentes.

MÉTHODOLOGIE : Au moyen d'un examen rétrospectif des dossiers, les auteurs ont recueilli des données sur l'anxiété, la douleur et l'invalidité fonctionnelle auprès de 655 enfants évalués dans une clinique multidisciplinaire de la douleur pendant une période de trois ans.

RÉSULTATS : Environ $11 \%$ des enfants et des adolescents ont déclaré des symptômes d'anxiété élevés sur le plan clinique, les taux élevés entre les dimensions d'anxiété oscillant entre 14 \% (anxiété sociale, inquiétude) à $27 \%$ (anxiété physiologique). De plus, une proportion remarquable $31 \%$ des membres de de l'échantillon minimisaient potentiellement leur anxiété en réagissant d'une manière souhaitable sur le plan social. L'anxiété s'associait de manière linéaire à une invalidité fonctionnelle plus importante liée à la douleur, mais n'y était pas corrélée directement. Les analyses de modération révèlent qu'à un faible taux d'inquiétude, les taux de douleur plus élevés s'associaient à une invalidité fonctionnelle plus marquée, tandis qu'à des taux d'inquiétude élevés, la douleur ne permettait plus de prédire le taux d'invalidité fonctionnelle.

CONCLUSIONS : Ces observations étayent la prévalence d'anxiété chez les enfants et les adolescents ayant des douleurs chroniques et élargissent la portée d'études récentes sur les liens complexes entre la douleur, l'anxiété et l'incapacité liée à la douleur.

as a whole, these patients suffer from higher levels of anxiety symptoms compared with well peers, the prevalence rates of clinically elevated anxiety symptoms in a sample of patients with diverse pediatric chronic pain conditions have not been previously reported. In addition, a more focused evaluation across complex pain conditions is needed to more fully understand the prevalence and impact of anxiety in pediatric chronic pain.

It is unclear whether psychological distress is a precursor to (12) or consequence of (11) living with chronic pain; however, psychological distress has generally been found to be associated with increased functional disability $(13,14)$. Specifically, previous studies have found a linear relationship between heightened anxiety and functional disability $(11,15)$. A recent study conducted by Cohen et al (16) examined the moderating impact of anxiety on the relationship between pain and disability. They found that in the context of high levels of anxiety, pain was unrelated to physical functioning, school attendance and physician visits, whereas when anxiety was low, pain consistently predicted disability. This unique and interesting finding suggests that anxiety may play a key role in maintaining disability by driving avoidant behaviours, thus perpetuating a vicious cycle of avoidance, which in turn may further heighten anxiety. Research involving adults also provides support for this hypothesis wherein anxiety predicted physical complaints

Division of Pain Medicine, Department of Anesthesiology, Perioperative and Pain Medicine, Children's Hospital Boston Eु Department of

Psychiatry, Harvard Medical School, Boston, Massachusetts, USA

Correspondence: Dr Laura E Simons, Pain Treatment Service, Children's Hospital Boston, 300 Longwood Avenue, Boston, Massachusetts 02215 ,

USA. Telephone 617-919-4677, fax 617-730-0759, e-mail Laura.Simons@childrens.harvard.edu 
beyond the impact of pain (17), and led to avoidance of activities and worsening of disability in chronic pain patients (18). Furthermore, specific treatments that target anxiety and pain-related fears have resulted in reductions in both anxiety and functional disability (19).

Recognizing the important role of anxiety as it relates to painrelated outcomes in children and adolescents, the current investigation assessed anxiety symptoms within a large tertiary care pain clinic sample to examine the prevalence rates of anxiety across complex chronic pain conditions; the dimensions of anxiety and their relation to functional disability; and whether dimensions of anxiety moderate the relation between pain and functional disability. Based on previous research, we hypothesized that children and adolescents with abdominal pain (20) and diffuse pain (6) would report higher levels of anxiety than patients with other chronic pain conditions. We also predicted that anxiety would be linearly associated with functional disability. Finally, based on the Cohen et al (16) findings, we anticipated that high levels of anxiety, not pain, would predict high levels of functional disability, whereas at low levels of anxiety, pain would be associated with greater disability.

\section{METHODS}

\section{Participants}

All patients eight to 17 years of age, with at least three months' duration of chronic pain who underwent a multidisciplinary pain evaluation at a tertiary pain clinic in a large, American pediatric hospital between February 2003 and October 2006 were included in the present retrospective chart review. The total sample included 655 patients who were primarily Caucasian $(91.9 \%)$ and female $(75.1 \%)$, reflective of the population of children seen in this tertiary care clinic setting. The mean $( \pm$ SD) age was $13.9 \pm 2.38$ years. Primary pain diagnoses included headache (29.1\%; including migraine, tension-type headache, combined and daily chronic headache), neuropathic pain (21.3\%; including complex regional pain syndrome and neuralgia), musculoskeletal pain (23.9\%; including juvenile rheumatoid arthritis and hypermobility syndromes), abdominal pain (11.2\%; including functional abdominal pain and inflammatory bowel disease), diffuse pain $(8.1 \%$; including fibromyalgia or description of pain in three or more areas without a clear etiology) and other pain (6.3\%; eg, chest, ear, bladder). At the time of the evaluation, patients' mean duration of pain was greater than two years $(28.71 \pm 30.42$ months, range three to 178 months).

Family socioeconomic status based on the four factor index of social status (21) ranged from 21 (semi-skilled workers) to 66 (business owner, professional), with a mean of $48.11 \pm 10.01$ (minor professional, technical). The majority of mothers $(74.1 \%)$ and fathers $(71.5 \%)$ were college graduates.

\section{Measures}

Functional Disability Inventory: The Functional Disability Inventory (FDI) $(22,23)$ assesses children's self-reported difficulty in physical and psychosocial functioning due to their physical health. The instrument consists of 15 items concerning perceptions of activity limitations during the previous two weeks; total scores are computed by summing the items. Higher scores indicate greater disability. The FDI has demonstrated reliability and validity $(22,23)$; alpha reliability for the current sample was 0.89 .

Revised Children's Manifest Anxiety Scale: The Revised Children's Manifest Anxiety Scale $(24,25)$ is a 37 -item questionnaire that assesses symptoms of anxiety. Total anxiety scores are calculated by summing all items with the exception of the lie scale items. Subscales consist of physiological anxiety, worry, social anxiety and a lie scale, which assesses underreporting of symptoms as a result of social desirability. The Revised Children's Manifest Anxiety Scale is a wellvalidated and reliable measure of anxiety $(24,25)$. Alpha reliability for the total score in the current sample was 0.88 .

Pain rating: As part of the semistructured interview with the clinical psychologist, children were asked to provide their current pain rating on a standard 11-point numerical rating scale (26) from 0 (no pain) to 10 (most pain possible).

Basic demographic information: Parents provided basic demographic information (eg, child's age and sex, parents' occupations, education, and marital status) on the Pain Treatment Service Demographic Information form.

\section{Procedure}

Approval from the hospital's Institutional Review Board was obtained before conducting the retrospective chart review. All measures completed in the present study were part of standard clinical care. All of the questionnaires were mailed to families before the child's multidisciplinary pain clinic evaluation. Parents and children were asked to complete the questionnaires individually and return them on the date of the evaluation. If parents and children had not completed the questionnaires before the appointment, they were asked to do so when they arrived for their evaluation. Children then underwent evaluation by a physician, physical therapist and clinical psychologist. All questionnaires were reviewed by the psychologist before the clinical interview. Patients' pain diagnoses, assigned by a pain management physician during the multidisciplinary evaluation, were obtained from a medical record review.

\section{Statistical analyses}

Analyses were conducted using SPSS version 19 (IBM Corporation, USA). Descriptive statistics were used to calculate means, SDs and frequencies. Correlation analyses were conducted to examine the patterns of relationships among the variables of interest. One-way ANOVAs were conducted to examine differences across pain diagnostic groups. Finally, a series of hierarchical multiple regression analyses were conducted to examine the extent to which children's anxiety symptoms moderated the relationships between children's current pain and functional disability. Tests of moderation used the data analytic technique described by Baron and Kenny (27), and Holmbeck (28). Scores on the FDI constituted the dependent variable for each analysis. In the first step, current pain and anxiety symptomatology (total anxiety, physiological anxiety, worrying or social anxiety) were entered. In the second step, the two-way interactions between current pain and children's anxiety were entered. Evidence of children's anxiety moderating the relationships between current pain and functional disability was obtained when significant interactions between children's pain and anxiety predicted children's functional disability.

\section{Descriptive data}

\section{RESULTS}

Regarding overall anxiety symptoms, $11 \%$ of the total sample reported clinically significant anxiety levels, with T-scores $>65$. Elevated levels of anxiety for each subscale (subscale score $>13$ ) were also examined: $26.6 \%$ of participants reported clinically significant physiological anxiety, $14.7 \%$ reported clinically significant worrying and $14 \%$ reported clinically significant social anxiety. Notably, $31.1 \%$ of the sample reported clinically elevated lie scale scores, suggesting that one-third of the sample was likely underreporting symptoms to present favourably. Table 1 details the frequency of clinically elevated anxiety symptoms across pain groups and dimensions of anxiety. The 'other pain' group was not examined because they represented several different pain diagnoses with too few in any category to be examined independently.

As expected, total anxiety was associated with functional disability $(\mathrm{r}=0.25 ; \mathrm{P}<0.001)$, but was not associated with pain $(\mathrm{r}=0.04$, $\mathrm{P}$ not significant). However, pain was associated with functional disability $(\mathrm{r}=0.33 ; \mathrm{P}<0.001)$. As indicated in Table 2 , each dimension of anxiety (eg, physiological, worry and social anxiety) was significantly correlated with functional disability. In addition, patients' lie subscale scores were significantly negatively correlated with each dimension of anxiety, indicating that patients who reported greater social desirability concerns reported lower levels of each type of anxiety. 
TABLE 1

Frequency of clinically significant anxiety according to pain diagnostic group and anxiety dimension

\begin{tabular}{|c|c|c|c|c|c|c|}
\hline \multirow[b]{2}{*}{ Pain group } & \multicolumn{6}{|c|}{ Pain groups } \\
\hline & Diffuse $(n=54)$ & Headache $(n=190)$ & Abdominal $(n=73)$ & Neuropathic $(n=139)$ & Musculoskeletal $(n=156)$ & $\chi^{2}$ \\
\hline Total, & 25.9 & 10.5 & 11 & 10.8 & 7.7 & $13.74^{\star \star}$ \\
\hline Physiological, \% & 35.2 & 25.3 & 41.1 & 25.2 & 21.8 & $11.82^{*}$ \\
\hline Social, \% & 31.5 & 13.7 & 12.3 & 15.1 & 9.6 & $16.09^{* *}$ \\
\hline Lie scale, \% & 25.9 & 32.1 & 20.5 & 38.1 & 28.8 & 8.15 \\
\hline
\end{tabular}

Data presented as $\%$ unless otherwise indicated. Numbers in bold highlight the highest $\%$ across pain subgroups. ${ }^{\star} P<0.05$, ${ }^{\star *} P<0.01$

TABLE 2

Correlations ( $r$ ) between anxiety dimensions and functional disability

\begin{tabular}{|c|c|c|c|c|c|c|c|c|}
\hline \multirow[b]{2}{*}{ Variable } & \multicolumn{7}{|c|}{$\mathbf{r}$} & \multirow[b]{2}{*}{ Mean \pm SD } \\
\hline & 2 & 3 & 4 & 5 & 6 & 7 & 8 & \\
\hline 1. Age & $0.09 *$ & 0.04 & $0.15^{\star \star}$ & $0.22^{\star \star}$ & 0.07 & $0.20 * *$ & -0.03 & $13.89 \pm 2.38$ \\
\hline 2. Pain & - & $0.33^{\star \star}$ & 0.04 & $0.08^{\star}$ & -0.03 & $0.09^{\star}$ & $0.08^{\star}$ & $4.23 \pm 2.91$ \\
\hline 3. Functional disability & & - & $0.25^{\star \star}$ & $0.29 \star \star$ & $0.15^{\star \star}$ & $0.23^{\star \star}$ & -0.03 & $20.94 \pm 12.18$ \\
\hline 4. Total child anxiety & & & - & $0.81^{\star \star}$ & $0.88^{\star *}$ & $0.83^{\star \star}$ & $-0.20^{\star \star}$ & $48.52 \pm 12.26$ \\
\hline 5. Physiological anxiety & & & & - & $0.59^{* *}$ & $0.60^{\star *}$ & $-0.17^{\star \star}$ & $10.41 \pm 3.55$ \\
\hline 6. Worrying & & & & & - & $0.66^{\star *}$ & $-0.14^{\star *}$. & $8.53 \pm 3.57$ \\
\hline 7. Social anxiety & & & & & & - & $-0.24^{\star \star}$ & $9.05 \pm 3.05$ \\
\hline 8. Lie scale & & & & & & & - & $10.97 \pm 3.66$ \\
\hline
\end{tabular}

${ }^{*} P<0.05,{ }^{*} P<0.01$

Anxiety according to pain diagnosis

Beyond prevalence of clinically significant anxiety, dimensions of anxiety (eg, worrying, physiological, social) were examined to determine whether they varied among primary pain diagnoses using oneway ANOVAs and Bonferroni post hoc $t$ tests.

Total anxiety: A one-way ANOVA indicated that there were significant differences in total anxiety according to pain diagnosis, $\mathrm{F}(4$, $607)=4.22, \mathrm{P}<0.01$. Post hoc results indicated that children with diffuse pain reported significantly higher levels of total anxiety $(53.40 \pm 13.7)$ than children with musculoskeletal pain $(47.3 \pm 11.5$, $\mathrm{P}<0.05)$, neuropathic pain $(47.7 \pm 12.3, \mathrm{P}<0.05)$ and headache pain (48.2 $\pm 12.7, \mathrm{P}=0.05)$.

Physiological anxiety: A one-way ANOVA indicated that there were significant differences in patients' reports of physiological anxiety according to pain diagnosis, $\mathrm{F}(4,607)=5.22, \mathrm{P}<0.001$. Post hoc results indicated that children with diffuse pain $(11.8 \pm 3.13)$ and abdominal pain (11.6 \pm 3.24$)$ reported significantly more physiological anxiety than children with musculoskeletal pain $(10.1 \pm 3.37, \mathrm{P}<0.05)$, children with headaches $(10.2 \pm 3.53, \mathrm{P}<0.05)$ and children with neuropathic pain $(10.1 \pm 3.37, \mathrm{P}<0.05)$.

Worrying: A one-way ANOVA indicated that there were significant differences in patients' worrying according to pain diagnosis, $\mathrm{F}(4$, $607)=2.36, P=0.05$. Although none of the post hoc analyses revealed significant differences by diagnosis, it appears that the diffuse pain $(9.41 \pm 4.07)$ and abdominal pain $(9.36 \pm 3.23)$ groups reported higher worry than the other diagnostic groups (headache, $8.70 \pm 3.70$; neurological, 8.35 \pm 3.56 ; and musculoskeletal, $8.14 \pm 3.36$ ), likely driving this omnibus finding.

Social anxiety: A one-way ANOVA indicated that there were significant differences in patients' social anxiety symptoms according to pain diagnosis, $\mathrm{F}(4,607)=2.56, \mathrm{P}<0.05$. Although none of the post hoc analyses revealed significant differences according to diagnosis, it appears that the diffuse pain $(10.1 \pm 3.55)$ and abdominal pain $(9.64 \pm 2.78)$ groups reported higher social anxiety symptoms than the other diagnostic groups (headache, 8.88 \pm 3.17 ; neurological, $8.92 \pm 3.02$; and musculoskeletal, $8.91 \pm 3.04$ ), likely driving this omnibus finding.

Lie scale: A one-way ANOVA indicated that there were no significant differences in patients' lie scale scores according to pain diagnosis, $\mathrm{F}(4,607)=1.16, \mathrm{P}=0.33$.
Does children's anxiety moderate the relation between pain and functional disability?

Using hierarchical multiple regression analyses, it was examined whether children's anxious symptoms moderated the relationship between current pain rating and children's functional disability, illustrated in Table 3. While results indicated significant main effects for multiple types of anxiety and pain on disability, the only significant interaction that emerged was between pain and worrying. The final equation was significant, $F(3,624)=34.47, P<0.001, R^{2}=0.14$. To examine the nature of the interaction effect, regression lines were plotted for patients with high (+1 SD) and low ( $-1 \mathrm{SD})$ levels of anxiety. This interaction is illustrated in Figure 1. For children and adolescents who reported lower levels of worry, higher levels of pain were associated with higher levels functional disability. However, for children and adolescents who reported higher levels of worrying, the level of pain did not predict functional disability.

\section{DISCUSSION}

The present study examined the prevalence of anxiety in patients with diverse chronic pain complaints. Results indicated that although only a small percentage of patients reported clinically significant levels of total anxiety, almost one-third of the participants reported clinically significant levels of physiological anxiety, indicating that anxiety about somatic symptoms and physical complaints tends to be high in patients with chronic pain. There was also a consistent pattern among children and adolescents with diffuse and abdominal pain complaints. Overall, a higher percentage of these patients reported clinically elevated anxiety symptoms, and their scores were significantly higher when compared with children and adolescents with headache, musculoskeletal pain and neuropathic pain. However, while statistically significant, the differences in scores were small, thus suggesting that while patients with diffuse pain in particular may be more at risk for clinically significant anxiety, the best course of action is evaluating a patient's anxiety symptoms regardless of pain diagnosis.

We also found that patients' level of worrying moderated the relationship between their current pain and functional disability. Specifically, we found that for patients with lower levels of worry, higher levels of pain were associated with greater functional disability. However, for patients who tended to be high in worrying, even low levels of pain were associated with high levels of disability. This 
TABLE 3

Child anxiety symptoms and pain on children's functional disability

\begin{tabular}{|c|c|c|c|c|c|}
\hline Variables & $\beta$ & Beta & $t$ & $\begin{array}{c}\mathbf{R}^{2} \\
\text { change }\end{array}$ & $\begin{array}{c}\text { Cohen's } \\
\mathbf{f}\end{array}$ \\
\hline \multicolumn{6}{|l|}{ Total anxiety } \\
\hline Step 1: Predictor variables & & & & 0.17 & 0.20 \\
\hline Total anxiety & 0.25 & 0.25 & $6.78^{\star \star \star}$ & & \\
\hline Pain & 1.36 & 0.32 & $8.80^{\star \star \star}$ & & \\
\hline Step 2: Two-way interaction & & & & 0.00 & 0.00 \\
\hline Total anxiety $\times$ pain & -0.02 & -0.26 & -1.58 & & \\
\hline \multicolumn{6}{|l|}{ Physiological anxiety } \\
\hline Step 1: Predictor variables & & & & 0.18 & 0.22 \\
\hline Physiological anxiety & 0.96 & 0.27 & $7.41^{\star \star \star}$ & & \\
\hline Pain & 1.31 & 0.31 & $8.55^{\star \star *}$ & & \\
\hline Step 2: Two-way interaction & & & & 0.00 & 0.00 \\
\hline Physiological anxiety $\times$ pain & 0.03 & 0.09 & 0.64 & & \\
\hline \multicolumn{6}{|l|}{ Worry anxiety } \\
\hline Step 1: Predictor variables & & & & 0.14 & 0.16 \\
\hline Worry anxiety & 0.58 & 0.17 & $4.53^{\star \star \star}$ & & \\
\hline Pain & 1.42 & 0.34 & $9.02^{\star \star \star}$ & & \\
\hline Step 2: Two-way interaction & & & & 0.01 & 0.01 \\
\hline Worry anxiety $\times$ pain & -0.09 & -0.22 & $-1.97^{*}$ & & \\
\hline \multicolumn{6}{|l|}{ Social anxiety } \\
\hline Step 1: Predictor variables & & & & 0.15 & 0.18 \\
\hline Social anxiety & 0.86 & 0.21 & $5.76^{\star \star *}$ & & \\
\hline Pain & 1.31 & 0.31 & $8.46^{\star \star \star}$ & & \\
\hline Step 2: Two-way interaction & & & & 0.00 & 0.00 \\
\hline Social anxiety × pain & -0.05 & -0.12 & -0.95 & & \\
\hline \multicolumn{6}{|l|}{ Defensiveness } \\
\hline Step 1: Predictor variables & & & & 0.11 & 0.12 \\
\hline Lie scale & -0.19 & -0.06 & -1.51 & & \\
\hline Pain & 1.41 & .33 & $8.83^{\star \star \star}$ & & \\
\hline Step 2: Two-way interaction & & & & 0.00 & 0.00 \\
\hline Lie scale $\times$ pain & 0.02 & 0.07 & 0.42 & & \\
\hline
\end{tabular}

${ }^{*} P<0.05,{ }^{* *} P<0.01,{ }^{* \star *} P<0.001 . f^{2}$ effect sizes of $0.02,0.15$, and 0.35 are considered small, medium and large (Cohen J. Statistical Power Analysis for the Behavioral Sciences, 2nd edn. Hillsdale: Lawrence Erlbaum, 1988).

finding highlights the importance of worrying in the experience of disability, and suggests that patients who are prone to worrying may have greater impairments in functioning and activities of daily living, even when they experience lower levels of chronic pain. Based on our clinical experience, many of our patients endorse high levels of worrying, particularly regarding academic or athletic performance and, therefore, the dimension of worry may be particularly important to understanding the relationship between pain and disability in pediatric patients with diverse chronic pain complaints

In addition, we found that one-third of the patients had elevated defensiveness or 'lie' scale scores, indicating that they were likely under-reporting their psychological distress due to a desire to present favourably. This phenomenon has been documented previously (29) because pediatric patients with chronic pain often want to legitimize the physical nature of their pain and downplay any emotional contributors, particularly when it has been suggested by previous health care providers that patients' pain is "all in their heads". Patients presenting to a multidisciplinary pain treatment service are typically seeking a medical diagnosis for their pain and, therefore, may under-report their psychological distress to maintain a focus on physical explanations for, and contributors to, their pain. Although there were no significant differences across diagnostic groups on social desirability (lie scale), the overall high percentage of children presenting in a socially desirable manner may reflect what we observe clinically wherein many of these patients struggle to obtain an accurate diagnosis and their pain

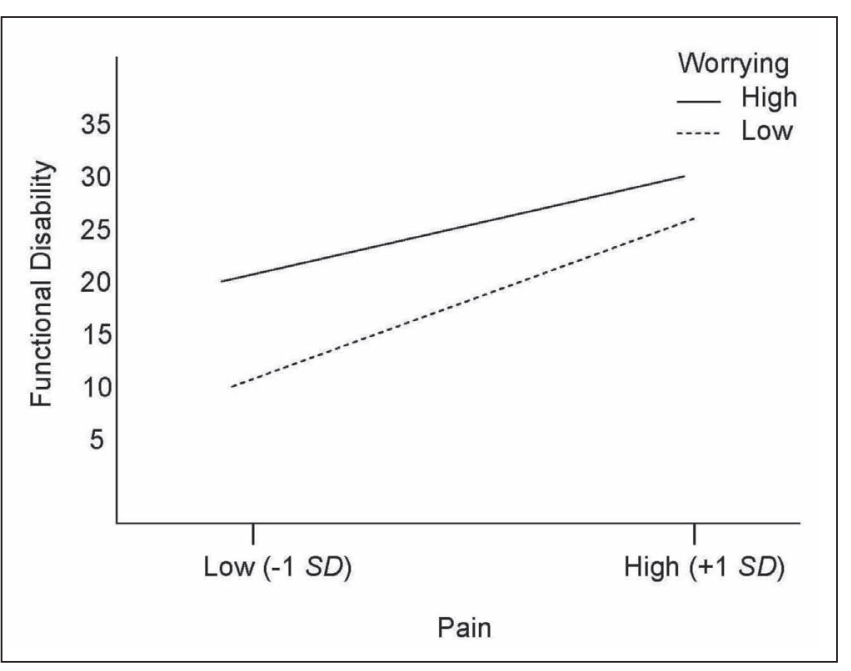

Figure 1) Estimated regression lines showing predicted somatic symptom scores for patients with low (-1 standard deviation [SD]) and high (+1 SD) levels of worrying. Graphed lines were plotted by selecting values $1 \mathrm{SD}$ above and below the mean for pain and worrying; these values were multiplied by their unstandardized regression coefficients to obtain values for plotting the predicted regression lines

is often labelled as psychological before presenting for evaluation at our clinic, and may also reflect the particular vulnerability that children experience of the pain being labelled 'psychological'. Within the context of anxiety, it also is likely that some patients who are indeed socially anxious may want to present themselves in a socially desirable manner. It would be interesting for future research to investigate social desirability and anxiety among a community sample with chronic pain to further assess the role of anxiety in pediatric chronic pain.

Consistent with previous research showing higher levels of anxiety symptoms among children and adolescents with diffuse pain complaints (6) and abdominal pain (30), patterns of differentiation did emerge in this cohort of patients who presented to the same tertiary care pain clinic. Specifically, it appears that physiological anxiety is particularly heightened among children with abdominal pain complaints, with $41 \%$ reporting clinically significant symptoms, while all domains of anxiety symptoms were particularly high among children with diffuse pain complaints, a finding consistent in research examining youth with fibromyalgia (6). These findings suggest that anxiety may differentiate across pain populations, and that children and adolescents with diffuse pain may be particularly vulnerable to anxiety. It would be interesting for future research to examine whether anxiety symptoms arise in the context of pain or whether patients with diffuse pain may be temperamentally more anxious than children with other types of chronic pain. Given the small difference detected in our large sample, replication of these findings is needed, particularly because the differences observed here, while statistically significant, may not be associated with clinical significance.

The study findings must be interpreted in light of their limitations. First, the study was retrospective and cross-sectional in design, with data drawn from chart review procedures. The tertiary clinic-based sample may not be fully representative of the larger population of all children who experience chronic pain. Although the high numbers of female and Caucasian patients are similar to demographic patterns reported in other pediatric multidisciplinary chronic pain clinic samples $(11,13)$, and research documents sex and ethnic discrepancies in those who seek treatment for chronic pain $(31,32)$, the predominance of girls in the current sample and the lack of ethnic heterogeneity limit the generalizability of the findings. Finally, given the large sample size in the present study and its effects on achieving statistical significance, it is important to address the clinical meaningfulness of these results. Although there were some statistically significant differences in 
reports of anxiety according to patients' pain diagnoses, overall, these differences were quite small and perhaps not clinically significant.

Despite these limitations, results of the present study suggest that anxiety is an important factor in pediatric chronic pain. Given that anxiety could be a factor in the exacerbation and maintenance of pediatric chronic pain, highlighting these issues in treatment is important. These findings highlight the importance of screening for anxiety among children with chronic pain and underscores that patients often present themselves in a socially desirable manner for evaluation. Discussing the potential benefit of psychological therapies with patients who present for pain evaluation should be a common practice to not only destigmatize psychological treatments for pain, but to ensure that patients receive adequate psychoeducation regarding the potential psychological impact of living with a chronic pain condition. Finally, the findings of the present study add to the current

\section{REFERENCES}

1. Shaffer D, Fisher P, Dulcan MK, et al. The NIMH Diagnostic Interview Schedule for Children Version 2.3 (DISC-2.3):

Description, acceptability, prevalence rates, and performance in the MECA Study. Methods for the Epidemiology of Child and Adolescent Mental Disorders Study. J Am Acad Child Adolesc Psychiatry 1996;35:865-77.

2. Grover RL, Ginsburg GS, Ialongo N. Psychosocial outcomes of anxious first graders: A seven-year follow-up. Depress Anxiety 2007;24:410-20.

3. Lipsitz JD, Masia C, Apfel H, et al. Noncardiac chest pain and psychopathology in children and adolescents. J Psychosom Res 2005;59:185-8.

4. Lipsitz JD, Gur M, Sonnet FM, et al. Psychopathology and disability in children with unexplained chest pain presenting to the pediatric emergency department. Pediatr Emerg Care 2010;26:830-6.

5. Di Lorenzo C. Visceral hyperalgesia in children with functional abdominal pain. J Pediatr 2001;139:838-43.

6. Kashikar-Zuck S, Parkins IS, Graham TB, et al. Anxiety, mood, and behavioral disorders among pediatric patients with juvenile fibromyalgia syndrome. Clin J Pain 2008;24:620-6.

7. Cruz N, O'Reilly J, Slomine BS, Salorio CF. Emotional and neuropsychological profiles of children with complex regional pain syndrome type-I in an inpatient rehabilitation setting. Clin J Pain 2011;27:27-34.

8. Knook LM, Konijnenberg AY, van der Hoeven J, et al. Psychiatric disorders in children and adolescents presenting with unexplained chronic pain: What is the prevalence and clinical relevancy? Eur Child Adolesc Psychiatry 2011;20:39-48.

9. Seshia SS. Chronic daily headache in children and adolescents. Can J Neurol Sci 2004:31:319-23.

10. Gauntlett-Gilbert J, Eccleston C. Disability in adolescents with chronic pain: Patterns and predictors across different domains of functioning. Pain 2007;131:132-41.

11. Eccleston C, Crombez G, Scotford A, Clinch J, Connell H. Adolescent chronic pain: Patterns and predictors of emotional distress in adolescents with chronic pain and their parents. Pain 2004;108:221-9.

12. Rivat $\mathrm{C}$, Becker $\mathrm{C}$, Blugeot $\mathrm{A}$, et al. Chronic stress induces transient spinal neuroinflammation, triggering sensory hypersensitivity and long-lasting anxiety-induced hyperalgesia. Pain 2010;150:358-68.

13. Kashikar-Zuck S, Goldschneider KR, Powers SW, Vaught MH, Hershey AD. Depression and functional disability in chronic pediatric pain. Clin J Pain 2001;17:341-9.

14. Vervoort T, Goubert L, Eccleston C, Bijttebier P, Crombez G. Catastrophic thinking about pain is independently associated with pain severity, disability, and somatic complaints in school children and children with chronic pain. J Pediatr Psychol 2006;31:674-83.

15. Peterson CC, Palermo TM. Parental reinforcement of recurrent pain: The moderating impact of child depression and anxiety on functional disability. J Pediatr Psychol 2004;29:331-41. knowledge base for medical and mental health professionals regarding the prevalence and role of anxiety among children and adolescents with chronic pain.

ACKNOWLEDGEMENTS: The authors thank the Sara Page Mayo Endowment for Pediatric Pain Research and Treatment and the Department of Anesthesiology, Perioperative and Pain Medicine at Children's Hospital Boston for their support.

GRANT SUPPORT: This work was supported by NIH Grant K23 HD067202 (to LS), by awards from the American Pain Society Future Leaders in Pain Small Grants Program (to LS) and the Children's Hospital Boston Career Development Fellowship Program (to LS). No conflicts of interest to report.

16. Cohen LL, Vowles KE, Eccleston C. The impact of adolescent chronic pain on functioning: Disentangling the complex role of anxiety. J Pain 2010;11:1039-46.

17. Somers TJ, Keefe FJ, Pells JJ, et al. Pain catastrophizing and painrelated fear in osteoarthritis patients: Relationships to pain and disability. J Pain Symptom Manage 2009;37:863-72.

18. Newcomer KL, Shelerud RA, Vickers Douglas KS, Larson DR, Crawford BJ. Anxiety levels, fear-avoidance beliefs, and disability levels at baseline and at 1 year among subjects with acute and chronic low back pain. PM R 2010;2:514-20.

19. Bailey KM, Carleton RN, Vlaeyen JW, Asmundson GJ. Treatments addressing pain-related fear and anxiety in patients with chronic musculoskeletal pain: A preliminary review. Cogn Behav Ther 2010;39:46-63.

20. Di Lorenzo C, Youssef NN, Sigurdsson L, Scharff L, Griffiths J, Wald A. Visceral hyperalgesia in children with functional abdominal pain. J Pediatr 2001;139:838-43.

21. Hollingshead A. Four Factor Index of Social Status. Department of Sociology, Yale University, 1975.

22. Claar RL, Walker LS. Functional assessment of pediatric pain patients: Psychometric properties of the functional disability inventory. Pain 2006;121:77-84.

23. Walker LS, Greene JW. The functional disability inventory: Measuring a neglected dimension of child health status. J Pediatr Psychol 1991;16:39-58.

24. Reynolds CR. Multitrait validation of the Revised Children's Manifest Anxiety Scale for children of high intelligence. Psychol Rep 1985;56:402.

25. Reynolds CR, Richmond BO. What I think and feel: A revised measure of children's manifest anxiety. J Abnorm Child Psychol 1978;6:271-80.

26. von Baeyer CL, Spagrud LJ, McCormick JC, Choo E, Neville K, Connelly MA. Three new datasets supporting use of the Numerical Rating Scale (NRS-11) for children's self-reports of pain intensity. Pain 2009;143:223-7.

27. Baron RM, Kenny DA. The moderator-mediator variable distinction in social psychological research: Conceptual, strategic, and statistical considerations. J Pers Soc Psychol 1986;51:1173-82.

28. Holmbeck GN. Toward terminological, conceptual, and statistical clarity in the study of mediators and moderators: Examples from the child-clinical and pediatric psychology literatures. J Consult Clin Psychol 1997;65:599-610.

29. Logan DE, Claar RL, Scharff L. Social desirability response bias and self-report of psychological distress in pediatric chronic pain patients. Pain 2008;136:366-72.

30. Campo JV, Bridge J, Ehmann M, et al. Recurrent abdominal pain, anxiety, and depression in primary care. Pediatrics 2004;113:817-24.

31. Keogh E, Eccleston C. Sex differences in adolescent chronic pain and pain-related coping. Pain 2006;123:275-84.

32. Nguyen M, Ugarte C, Fuller I, Haas G, Portenoy RK. Access to care for chronic pain: racial and ethnic differences. J Pain 2005;6:301-14. 


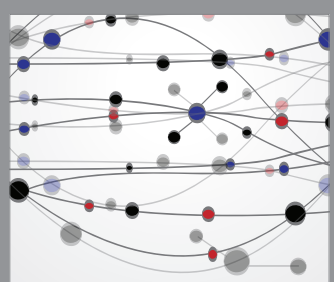

The Scientific World Journal
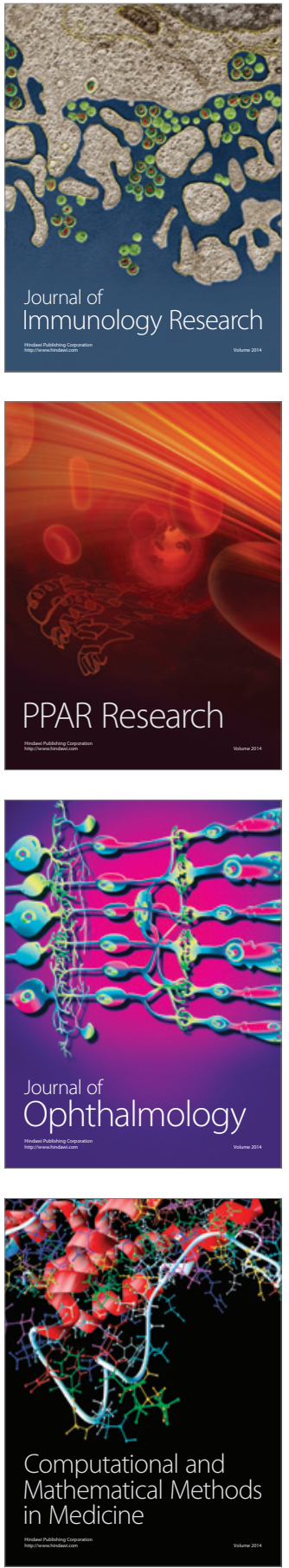

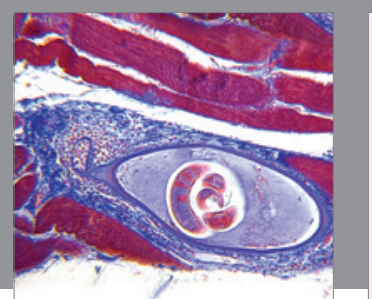

Gastroenterology Research and Practice

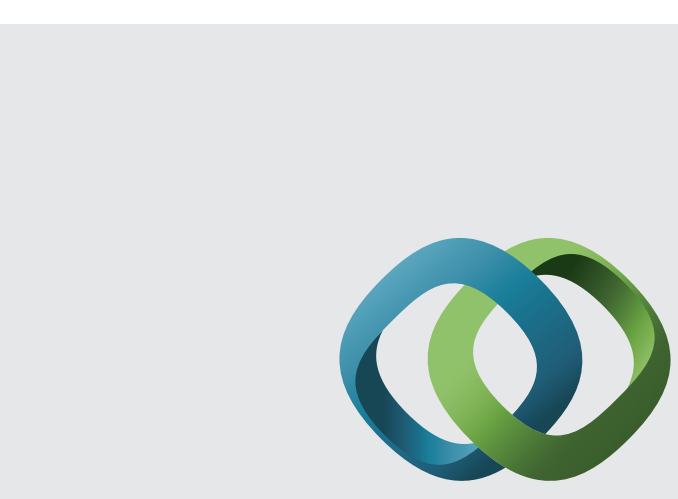

\section{Hindawi}

Submit your manuscripts at

http://www.hindawi.com
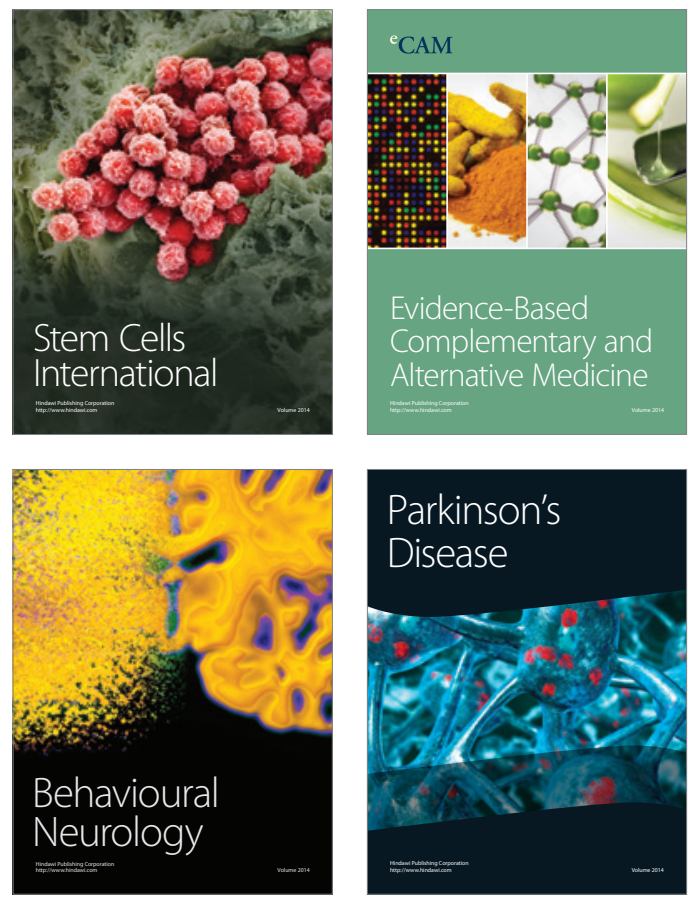
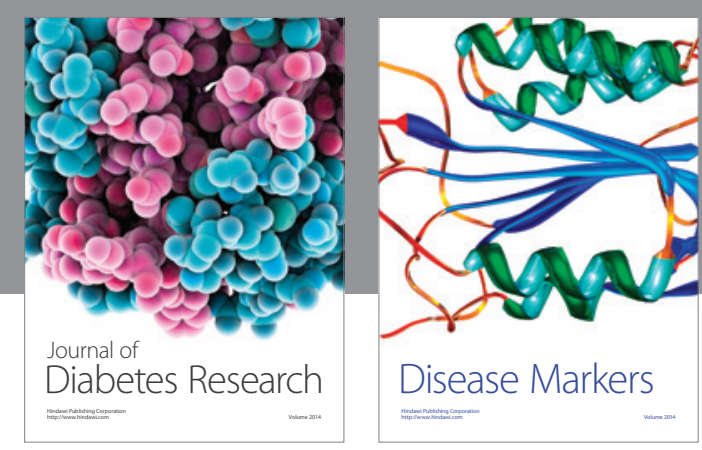

Disease Markers
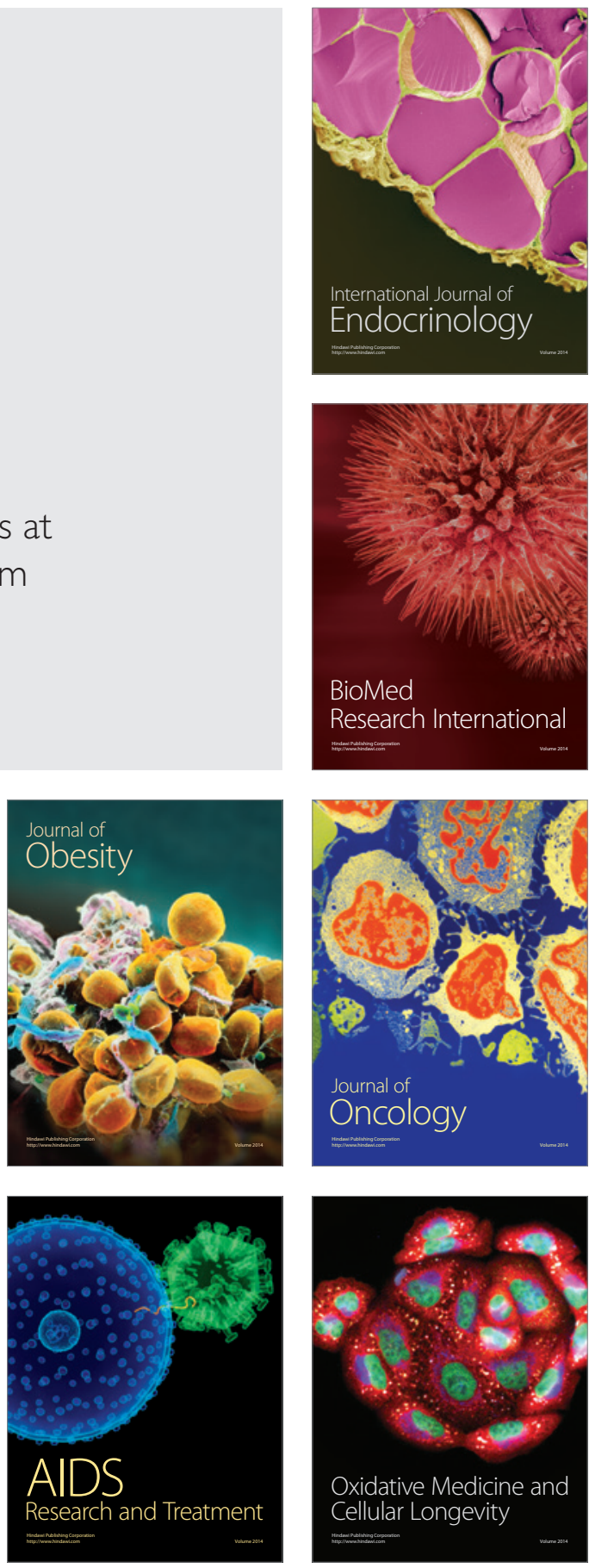